\title{
Determinação do Valor Residual da Natura S.A.
}

\author{
Determination of the Residual Value of Natura S.A.
}

\section{Ricardo Goulart Serra ${ }^{1}$}

\begin{abstract}
Resumo
Este é um caso de ensino que envolve a avaliação da Natura S.A., uma empresa de cosméticos sediada em Cajamar, S. Paulo. Alberto Sena e Luiza Spulet têm a missão de avaliá-la para o Sr. Charles lan Jones, administrador de um fundo de investimentos sediado em Nova lorque. O dilema abordado está restrito às premissas a serem adotadas para o cálculo da perpetuidade. As demais premissas de avaliação, simplificadas, são delineadas no texto do caso. A recomendação é que o caso de ensino seja aplicado em disciplinas de finanças corporativas ou avaliação de empresas em cursos de graduação, especialização ou pós-graduação. O objetivo do caso é explorar as alternativas de premissas para calcular a perpetuidade, proporcionando um ambiente para a discussão conceitual envolvendo a correta aplicação do modelo de Gordon e Shapiro (1956). Espera-se, com a sua aplicação, que os alunos compreendam que aplicar o referido modelo inadvertidamente pode resultar em valores potencialmente distorcidos e distantes da realidade. O professor/instrutor pode utilizar o caso para além da sua finalidade original (cálculo da perpetuidade), aplicando-o para explorar todas as etapas de avaliação de empresas e seus respectivos pontos passíveis de polêmicas, explorando opções de premissas (i) operacionais para a empresa e (ii) de custo de capital.
\end{abstract}

Palavras chave: Caso de Ensino. Avaliação de Empresas. Perpetuidade. Taxa de Crescimento.

\begin{abstract}
This is a teaching case that involves Natura S.A.'s (a cosmetic company headquartered in Cajamar, S. Paulo, Brazil) valuation. Alberto Sena and Luiza Spulet have the mission of valuing it for Mr. Charles lan Jones, manager of an investment fund headquartered in New York. The dilemma addressed is restricted to the assumptions to be adopted for the perpetuity calculation. The remaining assumptions, simplified, are outlined in the text of the case. The recommendation is that the teaching case be applied in disciplines of corporate finance or valuation in undergraduate, specialization or postgraduate courses. The purpose of the case is to explore the possibilities of assumption to calculate the perpetuity, providing an environment for the conceptual discussion involving the correct application of the Gordon and Shapiro's (1956) model. It is hoped, with its application, that students understand that applying the mentioned model inadvertently may result in distorted and far from reality values. The teacher/instructor can use the case beyond its original purpose (perpetuity calculation), applying it to explore all the stages of valuation and their respective points of controversy, exploring other (1) operational assumptions for the company and (2) cost of capital assumptions.
\end{abstract}

Key words: Teaching Case. Valuation. Perpetuity. Growth Rate.

\section{Introdução}

Era final da tarde de 31 de março de 2017 e Alberto Sena e Luiza Spulet, sócios da butique de investimentos WISE Finance, preparavam-se para deixar o escritório, quando o telefone tocou. Era Charles lan Jones, um canadense administrador de fundos de investimento sediado em Nova lorque. Após os cumprimentos de praxe, Charlie, como gostava de ser chamado, foi direto ao ponto: "Estamos pensando em comprar um grande volume de ações da Natura S.A. e gostaríamos da ajuda de vocês. Vocês poderiam preparar uma avaliação preliminar da empresa e enviar junto com um mandato de assessoria financeira na segunda feira?". Mesmo tendo apenas o final de semana para preparar o material, a dupla aceitou o pedido, afinal, conheciam bem o Charlie e sua forma de trabalhar.

Possui pós-doutorado pela FEA USP (2016), doutorado em administração financeira pela FEA USP (2011). Brasil. Afiliação: FECAP (Fundação Escola de Comércio Álvares Penteado); INSPER (Instituto de Ensino e Pesquisa) e USP (Universidade de São Paulo). Lattes: http://lattes.cnpq. br/0957404902684044 Email: ricardo.serra@usp.br 
Luiza dedicar-se-ia a preparar o mandato de assessoria e Alberto responsabilizar-se-ia pelo modelo de avaliação. Antes, porém, conversaram sobre as premissas.

\section{Breve Visão da Empresa}

A Natura é uma empresa brasileira presente no Brasil, Argentina, Chile, Colômbia, México, Peru, Venezuela, França e Austrália. Fundada em agosto de 1969, por Antônio Luiz Seabra, seu crescimento foi baseado na aposta de levar seus produtos à casa dos consumidores. Por meio do modelo de venda direta, oferece produtos de tratamento para o rosto, corpo, sabonetes, barba, desodorantes, óleos corporais, maquiagem, perfumaria, cabelos e proteção solar. No total, são mais de $\mathbf{8 7 0}$ produtos de 10 categorias e 29 submarcas. A marca Natura é líder na preferência de mercado (43\% de preferência contra 19\% da segunda colocada) e também em lealdade. A empresa conta com 5 unidades fabris no Brasil além de produção terceirizada no Brasil, Argentina, México, Colômbia e Austrália. Seus 9 centros de distribuição no Brasil separam diariamente aproximadamente 45 mil pedidos para serem distribuídos nos mais de 5.700 municípios brasileiros. Outros 5 centros de distribuição atendem suas operações internacionais. São aproximadamente 7,6 mil colaboradores (4,6 mil no Brasil) e 1,6 milhões de consultoras. Abriu o seu capital em maio de 2004, listando-se no mais alto nível de governança corporativa do Brasil, o Novo Mercado, levantando, na ocasião, $\mathrm{R} \$ 160$ milhões, no que foi considerada a reabertura do mercado brasileiro às ofertas públicas de ações. A ação da empresa rendeu $366 \%$ entre a abertura de capital e 31 de dezembro de 2016, quando o Ibovespa (Índice Bovespa) rendeu 216\%. Em 2016 a ação desvalorizou 1,2\% versus uma valorização de $42,9 \%$ do Ibovespa. Compõe os principais índices de governança e sustentabilidade: ISE, IGC, ITAG e Dow Jones Sustainability Index (Natura, 2017a, Natura 2017b). A receita líquida de 2016 foi de $R \$ 7,9$ bilhões, um crescimento de $0,2 \%$ em relação a 2015. O crescimento da receita líquida de 2014 para 2015 foi de $6,6 \%$. Nos últimos 3 anos, a margem bruta da empresa ficou estável no patamar de $69 \%$ a $70 \%$. No entanto, a margem operacional caiu de 18,4\% em 2014 para 13,7\% em 2016, com consequente queda da margem líquida de 10,0\% (2014) para 3,9\% (2016).

\section{As Premissas Preliminares}

Por se tratar de uma tarefa grande para ser executada em pouco tempo, os dois combinaram que não sofisticariam as premissas para esta avaliação preliminar.

"Sabemos como a equipe do Charlie trabalha. Lembra-se da primeira vez que o visitamos em Nova lorque, quando o Marco e a Bruna (equipe do Charlie) mostraram-nos um modelo de avaliação que intitulavam quick and dirty valuation?" - perguntou Luiza.

"Sim." - respondeu Alberto, emendando: "É bastante comum, apesar do nome um tanto pejorativo. Baseia-se na premissa de que a margem operacional da empresa mantém-se constante ao longo do horizonte de projeção, bem como o giro de ativo".

"Realmente, faz todo o sentido. Mantendo a margem e o giro constantes, mantém-se o retorno também constante, o que é bem adequado para um mercado maduro. Vamos adotar este raciocínio para esta avaliação preliminar. No futuro, podemos adotar eventuais melhorias. Portanto, podemos nos basear na margem e no giro de ativo históricos (tanto o giro de capital de giro líquido como o giro de ativo fixo líquido)." - completou a Luiza.

"O custo de capital pode ser calculado com as premissas usuais: (a) taxa livre de risco (rf) inferida pelo treasury bond americano, (b) prêmio país (pp) inferido pelo Emerging Market Bond Index do J.P. Morgan (EMBI+ Brasil), (c) prêmio de mercado (pm) de 5,5\%, que é o padrão da WISE Finance e (d) beta da própria empresa. O custo da dívida pode ser inferido a partir das dívidas existentes e os pesos do capital próprio e do capital de terceiros podem ser calculados a partir do firm value e equity value da própria empresa." - pensou em voz alta o Alberto.

"Embora existam outras abordagens para as premissas de custo de capital, por se tratar de um fundo baseado nos Estados Unidos, acho que esta abordagem, a princípio, não será questionada. Para 
terminarmos as projeções dos primeiros 5 anos, precisamos elaborar uma lógica para estimar a receita." - lembrou Luiza.

"Sim, esta é uma tarefa delicada." - corroborou Alberto.

\section{Estimando a Receita Líquida}

Alberto, lembrou-se: "No passado, quando tive que avaliar a Natura, eu estimei a receita com base na variação do PIB. Naquela ocasião, fiz uma regressão linear entre o crescimento da receita do setor de Higiene Pessoal, Perfumaria e Cosméticos (HPPC) e o crescimento do PIB (ambos em moeda forte). A partir (a) dos parâmetros estimados, (b) da projeção da variação do PIB e (c) da premissa que o market share da Natura mantém-se fixo (ou seja, a receita líquida da Natura cresce na mesma velocidade que a receita do setor de HPPC), estimei a receita da Natura".

"Gostei desta lógica de projeção!" - exclamou Luiza.

\section{Dilema}

"Parece-me que seu pedaço está bem encaminhado. Eu te ajudo a reunir as informações necessárias..." - comentava Luiza, quando foi interrompida pelo Alberto.

"Sim, mas e a perpetuidade? Qual crescimento usaremos? Consigo pensar em 3 possibilidades: (i) seguir com a lógica usada para o crescimento da receita ao longo do horizonte de projeção, (ii) usar o crescimento vegetativo do Brasil ou (iii) olhar o que outras instituições têm feito, genericamente" (laudos de avaliações públicos apresentadas na Tabela 8).

"São possibilidades a serem investigadas." - atalhou Luiza, seguindo: "Sugiro que você simule os três cenários para compararmos os resultados e pensar na razoabilidade de cada um deles. Tenho um material acadêmico que pode nos ajudar com esta discussão. Agora, vamos reunir as informações."

\section{Reunindo as Informações}

As informações reunidas foram:

(a) as demonstrações financeiras históricas da Natura para 2014, 2015 e 2016 (Tabela 1 - Balanço e Tabela 2 - Demonstrações de Resultados do Exercício).

(b) detalhamento de parte das demonstrações históricas da Natura (Tabela 3 - Endividamento).

(c) as informações da variação real da receita do setor de Higiene Pessoal, Perfumaria e Cosméticos e da variação real do PIB brasileiro (Tabela 4).

(d) o histórico do crescimento vegetativo (Tabela 5) e a expectativa futura: população atual de 207,9 milhões atingirá 228,6 milhões em 2030, ficando estável até 2040 e caindo para 200 milhões em 2100 (fonte: Banco Mundial e ONU).

(e) o histórico do yield to maturity do treasury bond do governo dos Estados Unidos e o histórico do Emerging Markets Bond Index brasileiro (Tabela 6).

(f) o beta alavancado $(0,840)$, o firm value $(R \$ 11.996,8$ milhões) e o equity value $(R \$ 9.905,6)$ da Natura em 29 de dezembro de 2016 (ComDinheiro ${ }^{\circledR}$ e Economática ${ }^{\circledR}$ ).

(g) as premissas macroeconômicas (Tabela 7).

(h) os laudos de avaliação (Tabela 8).

(i) a depreciação e amortização de 2016 de $\mathrm{R} \$ 260,8$ milhões e de 2015 de $\mathrm{R} \$ 239,2$ milhões.

(j) o CAPEX de 2016 de $R \$ 305,5$ milhões e de 2015 de $R \$ 457,4$ milhões.

(k) a quantidade de ações de 430,3 milhões.

(I) o preço por ação em 31 de dezembro de 2016 era $\mathrm{R} \$ 23,02$ e em 31 de março de 2017 era $\mathrm{R} \$ 29,01$. 
Observação: a conciliação dos itens (i) e (j) com o balanço da Tabela 2 só pode ser feita com as informações sobre as baixas contábeis e outras movimentações (transferências e variações cambiais).

\section{Pondo a Mão na Massa}

Reunidas as informações, despediram-se:

"Luiza, acho que você pode se basear no mandato do projeto 'Barca Velha'. Precisando de ajuda com o documento, mande-me um WhatsApp. Estarei em casa preparando o modelo de valuation. Estou bem animado e acredito que ficará bom. Vamos marcar de discutir a perpetuidade no domingo à tarde? Trarei tudo pronto!" - finalizou Alberto.

"Não terei dificuldades com a minha parte. Basear-me-ei no mandato da 'Barca Velha', como você acabou de sugerir. Eu reunirei o material que comentei para discutimos conceitualmente a taxa de crescimento na perpetuidade. Será ótimo e oportuno relembrar estas discussões. Também estou animada! Vemo-nos no domingo às 16:00 aqui no escritório. Eu trarei, além do material prometido, um lanchinho. Também estou disponível no WhatsApp." - despediu-se Luiza.

Apesar de 'terem perdido o final de semana', saíram bem animados com a tarefa que tinham pela frente. Luiza tinha a tarefa de preparar o mandato de assessoria financeira e Alberto tinha que fazer um modelo preliminar para calcular o valor da Natura, sendo que as premissas da perpetuidade eram o seu principal desafio. 


\section{ANEXO - TABELAS}

Tabela 1 - Balanço consolidado da Natura Cosméticos S.A. em 31 de dezembro dos respectivos anos.

\begin{tabular}{|c|c|c|c|}
\hline Ativo [R\$ mil] & 2016 & 2015 & 2014 \\
\hline Caixa e Equivalentes & 1.091 .470 & 1.591 .843 & 1.164 .174 \\
\hline Aplicações Financeiras & 1.207 .459 & 1.191 .836 & 531.812 \\
\hline Contas a Receber & 1.051 .901 & 909.013 & 847.487 \\
\hline Estoque & 835.922 & 963.675 & 889.977 \\
\hline Impostos a Compensar & 329.409 & 320.392 & 240.329 \\
\hline Instrumentos Derivativos & 0 & 734.497 & 317.023 \\
\hline Outros Ativos Circulantes & 286.739 & 307.450 & 248.482 \\
\hline Impostos a Compensar & 280.634 & 289.437 & 182.706 \\
\hline Imposto Diferido & 492.996 & 212.608 & 147.763 \\
\hline Depósitos Judiciais & 303.074 & 287.795 & 263.324 \\
\hline Outros Ativos não Circulantes & 23.033 & 17.604 & 85.655 \\
\hline Imobilizado e Intangível Brutos & 3.774 .225 & 3.679 .792 & 3.204 .757 \\
\hline (-) Depreciação e Amortização Acumuladas & $(1.255 .283)$ & $(1.110 .961)$ & $(923.406)$ \\
\hline Total do Ativo & 8.421 .579 & 9.394 .981 & 7.200 .083 \\
\hline Passivo e Patrimônio Líquido [R\$ mil] & 2016 & 2015 & 2014 \\
\hline Empréstimos e Financiamentos & 1.764 .488 & 2.161 .383 & 1.466 .599 \\
\hline Contas a Pagar & 814.939 & 802.887 & 599.621 \\
\hline Salários e Encargos a Pagar & 208.114 & 201.200 & 210.515 \\
\hline Impostos a Pagar & 1.075 .431 & 1.047 .961 & 715.468 \\
\hline Dividendos Declarados & 79.739 & 0 & 0 \\
\hline Provisões para Aquisição de não Controladores & 0 & 190.658 & 48.221 \\
\hline Instrumentos Derivativos & 73.502 & 0 & 0 \\
\hline Outros Passivos Circulantes & 161.686 & 168.831 & 78.572 \\
\hline Empréstimos e Financiamentos & 2.625 .683 & 3.374 .497 & 2.514 .611 \\
\hline Impostos a Pagar & 237.513 & 87.744 & 98.992 \\
\hline Imposto Diferido & 23.775 & 34.073 & 0 \\
\hline Provisões Trabalhistas, Cíveis e Tributárias & 93.624 & 77.858 & 75.763 \\
\hline Outros Passivos não Circulantes & 266.700 & 170.122 & 243.042 \\
\hline Patrimônio Líquido & 996.385 & 1.077 .767 & 1.148 .679 \\
\hline Total do Passivo e PL & 8.421 .579 & 9.394 .981 & 7.200 .083 \\
\hline
\end{tabular}

Fonte: Adaptada pelo autor das Demonstrações Financeiras da Natura Cosméticos S.A. (Natura, 2016 e Natura, 2015$).$

Tabela 2 - Demonstrações de Resultados dos Exercícios consolidado da Natura Cosméticos S.A. para os anos findos nos respectivos anos.

\begin{tabular}{lccc}
\hline DRE [R $\$$ mil] & $\mathbf{2 0 1 6}$ & $\mathbf{2 0 1 5}$ & $\mathbf{2 0 1 4}$ \\
\hline Receita Líquida & 7.912 .664 & 7.899 .002 & 7.408 .422 \\
Custo do Produto Vendido & $(2.446 .959)$ & $(2.415 .990)$ & $(2.250 .120)$ \\
Resultado Bruto & 5.465 .705 & 5.483 .012 & 5.158 .302 \\
Margem Bruta & $69,1 \%$ & $69,4 \%$ & $69,6 \%$ \\
Despesas com Vendas & $(3.110 .169)$ & $(3.020 .500)$ & $(2.680 .091)$ \\
Despesas Gerais e Administrativas & $(1.327 .093)$ & $(1.271 .533)$ & $(1.133 .346)$ \\
\hline
\end{tabular}




\begin{tabular}{lccc}
\hline Outras Receitas (Despesas) Operacionais & 54.425 & 65.790 & 19.807 \\
\hline Resultado Operacional & 1.082 .868 & 1.256 .769 & 1.364 .672 \\
Margem Operacional & $13,7 \%$ & $15,9 \%$ & $18,4 \%$ \\
Receita Financeira & 1.073 .288 & 1.927 .228 & 703.805 \\
Despesa Financeira & $(1.729 .297)$ & $(2.308 .627)$ & $(972.084)$ \\
LAIR & 426.859 & 875.370 & 1.096 .393 \\
Imposto de Renda e Contribuição Social & $(118.621)$ & $(352.638)$ & $(355.172)$ \\
\hline Lucro Líquido & 308.238 & 522.732 & 741.221 \\
\hline Margem Líquida & $3,9 \%$ & $6,6 \%$ & $10,0 \%$ \\
\hline
\end{tabular}

Fonte: Adaptada pelo autor das Demonstrações Financeiras da Natura Cosméticos S.A. (Natura, 2016 e Natura, 2015).

Tabela 3 - Endividamento da Natura Cosméticos S.A. em 31 de dezembro dos respectivos anos. Painel (a): Endividamento (agrupada por fornecedor de capital e/ou instrumento)

\begin{tabular}{lccc}
\hline [R $\$$ mil] & $\mathbf{2 0 1 6}$ & $\mathbf{2 0 1 5}$ & \\
\hline Em moeda local & & & $\mathrm{A}$ \\
FINEP & 149.916 & 160.752 & $\mathrm{~B}$ \\
Debêntures & 1.461 .237 & 1.461 .395 & $\mathrm{C}$ \\
BNDES & 118.497 & 170.300 & $\mathrm{D}$ \\
BNDES EXIM & 298.011 & 0 & $\mathrm{E}$ \\
Capital de Giro / NCE & 40.502 & 256.125 & $\mathrm{~F}$ \\
BNDES Finame & 8.313 & 13.592 & $\mathrm{G}$ \\
Arrendamento mercantil & 437.274 & 435.313 & $\mathrm{H}$ \\
FINEP Subvenção & 0 & 11 & $\mathrm{I}-\mathrm{K}$ \\
Nas moedas locais das subsidiárias & 217.732 & 256.338 & $\mathrm{~L}$ \\
\hline Em moeda estrangeira & & & $\mathrm{M}$ \\
\hline BNDES - US\$ & 31.985 & 51.628 & \\
Resolução 4.131/62 & 1.626 .704 & 2.730 .426 & \\
Total & 4.390 .171 & 5.535 .880 & \\
Curto Prazo & 1.764 .488 & 2.161 .383 & 3.374 .497 \\
Longo Prazo & 2.625 .683 & & \\
\hline Painel (b): ObservaçDes (custos & & & \\
\hline
\end{tabular}

\section{Painel (b): Observações (custos e avais ou garantias)}
A. $5 \%$ a.a. até $2019,3,5 \%$ a.a. até 2023 / aval da controladora
B. $107 \%$ a $108 \%$ do CDI, vencimentos em 2017,2018 e 2019 / sem garantia
C. TJLP $+0,5 \%$ a $3,96 \%$ a.a. / fiança bancária
D. $30 \%$ a Selic $+0,4 \%$ e $70 \%$ a TJLP / aval da Natura Cosméticos S.A.
E. $8 \%$ a.a. e $107 \%$ do CDI / aval da Natura Cosméticos S.A.
F. TJLP + 4,5\% a.a.; pré fixado a $6 \%$ - 10,5\% a.a./ alienação fiduciária; aval da Natura Cosméticos S.A. e notas promissórias
G. IPCA + 9\% a.a. / alienação fiduciária dos bens objeto do contrato de arrendamento mercantil
H. 6,3\% a.a / aval da Natura Cosméticos S.A.
I-K. Diversos / aval da Natura Cosméticos S.A. ou carta de fiança
L. Dólar $+1,8 \%$ a $2,3 \%$ a.a. / aval da Natura Cosméticos S.A. e carta de fiança bancária
M. Dólar + Libor $+1,32 \%$ a 2,90\% a.a. / aval da Indústria e Comércio de Cosméticos Natura Ltda.

Fonte: Adaptada pelo autor das Demonstrações Financeiras da Natura Cosméticos S.A. (Natura, 2016 e Natura, 2015). 
Tabela 4 - Histórico de crescimento do setor de Higiene Pessoal, Perfumaria e Cosméticos e do crescimento do PIB brasileiro (ambos em moeda constante).

\begin{tabular}{|c|c|c|c|c|c|}
\hline Ano & PIB (\%) & HPPC (\%) & Ano & PIB (\%) & HPPC (\%) \\
\hline 2006 & 3,96 & 15,0 & 2011 & 3,97 & 6,3 \\
\hline 2007 & 6,07 & 9,4 & 2012 & 1,92 & 8,8 \\
\hline 2008 & 5,09 & 5,5 & 2013 & 3,00 & 5,3 \\
\hline 2009 & $(0,13)$ & 9,6 & 2014 & 0,50 & 7,0 \\
\hline 2010 & 7,53 & 10,5 & 2015 & $(3,77)$ & $(9,3)$ \\
\hline
\end{tabular}

Fonte: Adaptada pelo autor de Abihpec (2016) e do Banco Central do Brasil (https://www.bcb.gov.br/).

Tabela 5 - Histórico do crescimento vegetativo brasileiro.

\begin{tabular}{cc}
\hline Ano & Crescimento (\%) \\
\hline 2000 & 1,51 \\
2001 & 1,49 \\
2002 & 1,46 \\
2003 & 1,42 \\
2004 & 1,35 \\
2005 & 1,26 \\
2006 & 1,17 \\
2007 & 1,08 \\
\hline
\end{tabular}

\begin{tabular}{cc}
\hline Ano & Crescimento (\%) \\
\hline 2008 & 1,02 \\
2009 & 0,99 \\
2010 & 0,97 \\
2011 & 0,95 \\
2012 & 0,94 \\
2013 & 0,91 \\
2014 & 0,89 \\
2015 & 0,86 \\
\hline
\end{tabular}

Fonte: Adaptada pelo autor de Banco Mundial (2016).

Tabela 6 - Retorno até o vencimento (yield to maturity) do título do tesouro americano de 10 anos (T-Bond) e Emerging Markets Bond Index (EMBI+ Brasil). Histórico de 1 mês findo em 31 de março de 2017.

\begin{tabular}{|c|c|c|c|c|c|}
\hline Data & T-Bond (\%) & EMBI (pontos base) & Data & T-Bond (\%) & EMBI (pontos base) \\
\hline $01 / 03 / 2017$ & 2,46 & 275 & $16 / 03 / 2017$ & 2,53 & 274 \\
\hline $02 / 03 / 2017$ & 2,49 & 280 & $17 / 03 / 2017$ & 2,50 & 272 \\
\hline 03/03/2017 & 2,49 & 273 & $20 / 03 / 2017$ & 2,47 & 269 \\
\hline 06/03/2017 & 2,49 & 272 & $21 / 03 / 2017$ & 2,43 & 277 \\
\hline 07/03/2017 & 2,52 & 274 & $22 / 03 / 2017$ & 2,40 & 280 \\
\hline 08/03/2017 & 2,57 & 287 & 23/03/2017 & 2,41 & 280 \\
\hline 09/03/2017 & 2,60 & 290 & 24/03/2017 & 2,40 & 278 \\
\hline $10 / 03 / 2017$ & 2,58 & 280 & $27 / 03 / 2017$ & 2,38 & 279 \\
\hline $13 / 03 / 2017$ & 2,62 & 286 & $28 / 03 / 2017$ & 2,42 & 278 \\
\hline $14 / 03 / 2017$ & 2,60 & 291 & $29 / 03 / 2017$ & 2,39 & 275 \\
\hline \multirow[t]{2}{*}{$15 / 03 / 2017$} & 2,51 & 282 & $30 / 03 / 2017$ & 2,42 & 274 \\
\hline & & & $31 / 03 / 2017$ & 2,40 & 270 \\
\hline
\end{tabular}

Fonte: Adaptada pelo autor de US Department of Treasury (https://www.treasury.gov/resource-center/data-chart-center/ interest-rates/Pages/TextView.aspx?data=yield) e IPEA (http://www.ipeadata.gov.br/). 
Tabela 7 - Premissas macroeconômicas (2016 é real e 2017 a 2021 são projetados).

\begin{tabular}{lcccccc}
\hline & $\mathbf{2 0 1 6} \mathbf{R}$ & $\mathbf{2 0 1 7} \mathbf{P}$ & $\mathbf{2 0 1 8} \mathbf{P}$ & $\mathbf{2 0 1 9} \mathbf{P}$ & $\mathbf{2 0 2 0} \mathbf{P}$ & $\mathbf{2 0 2 1} \mathbf{P}$ \\
\hline Variação do PIB (\%) & $(3,59)$ & 0,47 & 2,46 & 2,57 & 2,51 & 2,47 \\
Câmbio (R\$/US\$, fim de período) & 3,26 & 3,27 & 3,39 & 3,45 & 3,51 & 3,58 \\
IPCA (\%) & 6,28 & 4,09 & 4,38 & 4,31 & 4,28 & 4,19 \\
CPI (\%) & 1,28 & 2,65 & 2,38 & 2,64 & 2,32 & 2,20 \\
SELIC (\%, fim de período) & 13,75 & 8,76 & 8,63 & 8,74 & 8,62 & 8,54 \\
\hline
\end{tabular}

Obs.: CPI é Consumer Price Index, uma medida da inflação dos Estados Unidos da América.

Fonte: Adaptada pelo autor de Banco Central do Brasil (https://www.bcb.gov.br/) e The Statistics Portal (https://www.statista. com/statistics/244983/projected-inflation-rate-in-the-united-states/).

Tabela 8 - Laudos de avaliação selecionados. Fluxo de caixa do último ano do horizonte de projeção e fluxo de caixa ajustado para a base de cálculo da projeção.

Painel (a): Vigor Alimentos S.A. (elaborado pelo Credit Suisse em 29 de fevereiro de 2016)

\begin{tabular}{|c|c|c|c|}
\hline [US\$ Milhões] & & $2024 P$ & $2024 \mathrm{Aj}$ \\
\hline Resultado Operacional & & $1.090,4$ & $1.090,4$ \\
\hline (-) IR Operacional & & $(370,7)$ & $(370,7)$ \\
\hline (+) Depreciação & & 149,7 & 149,7 \\
\hline (-) CAPEX & & $(145,4)$ & $(149,7)$ \\
\hline (-) Investimento em CGL & & $(73,2)$ & $(73,2)$ \\
\hline (=) Fluxo de Caixa & & 650,8 & 646,5 \\
\hline WACC & $10,3 \%$ & & \\
\hline Crescimento & $1,9 \%$ & & \\
\hline
\end{tabular}

Observações: WACC e fluxo de caixa nominais em dólares americanos. Taxa de crescimento igual à inflação de longo prazo americana. Considere que a perpetuidade foi calculada como 646,5*(1+1,9\%)/(10,3\%-1,9\%), em 2024.

Painel (b): Brasmotor S.A. (elaborado pelo Santander em 7 de julho de 2016)

\begin{tabular}{|c|c|c|}
\hline [R\$ Milhões] & $2025 \mathrm{P}$ & $2026 \mathrm{Aj}$ \\
\hline Resultado Operacional & 800,0 & 847,5 \\
\hline (-) IR Operacional & $(237,9)$ & $(252,0)$ \\
\hline (+) Depreciação & 256,0 & 256,0 \\
\hline (-) CAPEX & $(306,8)$ & $(256,0)$ \\
\hline (-) Investimento em CGL & 24,8 & 25,9 \\
\hline (=) Fluxo de Caixa & 536,1 & 621,4 \\
\hline WACC & & \\
\hline Crescimento & & \\
\hline
\end{tabular}

Observações: WACC e fluxo de caixa nominais em reais. Taxa de crescimento igual à inflação de longo prazo brasileira. A alíquota de imposto considera os atuais benefícios fiscais. Considere que a perpetuidade foi calculada como $621,4 /(15,4 \%-4,5 \%)$, em 2025.

Painel (c): Gerdau S.A. (elaborado pelo BBI em 20 de março de 2017)

\begin{tabular}{|c|c|c|c|}
\hline [R\$ Milhões] & & $2021 \mathrm{P}$ & $2021 \mathrm{Aj}$ \\
\hline Resultado Operacional & & $6.381,0$ & $5.753,0$ \\
\hline (-) IR Operacional & & $(2.169,5)$ & $(1.956,0)$ \\
\hline (+) Depreciação & & $2.625,0$ & $2.625,0$ \\
\hline (-) CAPEX & & $(1.738,0)$ & $(2.625,0)$ \\
\hline (-) Investimento em CGL & & $(396,0)$ & $(270,0)$ \\
\hline (=) Fluxo de Caixa & & $4.702,5$ & $3.527,0$ \\
\hline WACC & $12,5 \%$ & & \\
\hline Crescimento & $4,2 \%$ & & \\
\hline
\end{tabular}

Observações: WACC e fluxo de caixa nominais em reais. Taxa de crescimento iqual à inflação de longo prazo brasileira. Parece ter ajustado o resultado operacional base para considerar os ciclos econômicos. Considere que a perpetuidade foi calculada como $3.527^{*}(1+4,2 \%) /(12,5 \%-4,2 \%)$, em 2021 .

Fonte: Adaptada pelo autor dos respectivos laudos de avaliação públicos no site da CVM (http://sistemas.cvm.gov.br/?opa). 


\section{ANEXO II - NOTAS DE ENSINO}

\section{Objetivo}

O caso de ensino foca em um dilema bem definido: como montar a perpetuidade para avaliar a Natura. Seu objetivo é explorar as possibilidades de premissas para calcular a perpetuidade. Espera-se, com a sua aplicação, que os alunos compreendam que empregar o modelo de Gordon e Shapiro (1956) inadvertidamente pode resultar em valores distorcidos e longe da realidade. Neste sentido, a discussão proposta está restrita a este ponto das projeções da Natura, embora diversos outros aspectos também sejam passíveis de discussão (projeções das demonstrações financeiras, estimação do custo de capital e até a própria metodologia adotada). Caso o professor/instrutor deseje, o caso de ensino é flexível e permite sua utilização para expor os alunos a todos estes outros aspectos da avaliação da Natura.

\section{Fontes e Coletas dos Dados}

Os dados foram obtidos de fontes públicas, basicamente de sites, sendo os mais importantes: (a) área de Relação com Investidores da Natura, (b) sistema de séries temporais do Banco Central do Brasil, (c) IPEA, (d) US Department of Treasury, (e) Banco Mundial e (f) Associação Brasileira da Indústria de Higiene Pessoal, Perfumaria e Cosméticos. As únicas exceções foram o beta, o firm value e o equity value da Natura em 31 de dezembro de 2016, que foram obtidos no sistema de informações da Economática ${ }^{\circledR}$ e no site ComDinheiro ${ }^{\circledR}$.

\section{Disciplinas Sugeridas, Relação com os Objetivos das Disciplinas e Aplicações}

As disciplinas sugeridas para a aplicação do caso são: Finanças Corporativas e Avaliação de Empresas, nos níveis de graduação, especialização e pós-graduação. Em Finanças Corporativas, o aluno aprende que o objetivo de uma empresa é agregar valor para o acionista (entre outros, dependendo da literatura). Portanto, valor é um dos temas abordados nesta disciplina. Além do mais, a construção do fluxo de caixa e do custo de capital são temas ligados às duas decisões empresariais (investimento e financiamento, respectivamente). Em Avaliação de Empresas, o aluno aprende a avaliar empresas pelos diferentes métodos, sendo a avaliação por fluxo de caixa descontado é um dos métodos mais relevantes, ao lado de avaliação por múltiplos. O caso expõe o aluno à prática da avaliação de uma empresa real, levando-o a colocar em prática os aprendizados conceituais. A aplicação principal do caso é a discussão conceitual e prática de como determinar a taxa de crescimento na perpetuidade. Esta aplicação pode ser por meio de (i) discussão em sala de aula, (ii) tarefa de casa ou (iii) avaliação de curso. Em todas estas aplicações o caso é flexível e permite ser aproveitado para muitas outras discussões relativas a todas as etapas da avaliação da Natura.

\section{Pré Requisitos}

Para a aplicação principal, o aluno deve conhecer a técnica de avaliação de empresas por fluxo de caixa descontado. Neste sentido, deve conhecer (a) o roteiro para a construção do fluxo de caixa para a empresa (investidores ou firma), (b) o cálculo do custo de capital médio ponderado (WACC - weighted average cost of capital) e (c) cálculo do valor residual por meio de uma perpetuidade (método de Gordon e Shapiro, 1956). Conhecimentos de análise das demonstrações financeiras e cálculo financeiro também são pré-requisitos.

Sugestão de bibliografia: Copeland, Koller e Murin (2002), Damodaran (2007), Martelanc, Pasin e Pereira (2010) e Serra e Wickert (2014).

\section{Preparação para o Caso}

Quando da distribuição do caso, o professor/instrutor pode, a seu julgamento, guiar os alunos nas Tabelas do Anexo (caso imagine que os alunos não tenham a experiência necessário para compreendêlas). 
O professor/instrutor deve pedir que o caso seja lido antes da aula de sua aplicação. Idealmente, para garantir a leitura, pode pedir que algumas questões sejam antecipadamente respondidas (por exemplo, para a aula anterior à aula da aplicação do caso). Sugestões de questões (lembrando que o foco do caso é definir as premissas do cálculo da perpetuidade):

(a) descreva a empresa (incluindo um breve sumário de suas demonstrações financeiras: receita líquida, crescimento, margens etc.),

(b) descreva a lógica sugerida para a projeção da receita líquida e do resultado operacional,

(c) descreva a lógica sugerida para a projeção das contas do capital de giro e do ativo fixo,

(d) indique as premissas sugeridas para a construção do custo de capital,

(e) os laudos de avaliação (Tabela 8) seguem uma mesma lógica para o cálculo da perpetuidade. Você consegue identificá-la? Caso afirmativo, descreva-a sucintamente,

(f) de maneira preliminar, qual alternativa de crescimento você entende ser a melhor para a construção da perpetuidade, entre as citadas no texto do caso?, e

(g) antevê alguma informação necessária que o caso não fornece? Qual(is)? Para que utilizaria esta(s) informação(ões) na construção da perpetuidade? Esta(s) informação(ões) pode(m) ser obtida(s) publicamente?

Outras atividades preparatórias podem ser concebidas pelo professor/instrutor.

\section{Plano de Aula Sugerido}

O plano de aula sugerido pode ser adaptado para considerar o nível de ensino em que o mesmo é aplicado (graduação, especialização e pós-graduação) bem como o escopo de aplicação do mesmo. Considerando o nível de pós-graduação e o escopo restrito à discussão sobre a taxa de crescimento na perpetuidade, sugere-se o plano apresentado no Quadro 1.

Quadro 1 - Sugestão de organização da aula.

\begin{tabular}{|l|c|}
\hline Tarefa & Tempo \\
\hline Revisão dos passos para avaliar uma empresa, incluindo o cálculo da perpetuidade & 15 minutos \\
\hline Apresentação do caso & 15 minutos \\
\hline Apresentação do custo de capital (números e premissas, brevemente) & 10 minutos \\
\hline Apresentação do fluxo de caixa (números e lógica, brevemente) & 20 minutos \\
\hline Cálculo da perpetuidade - alternativa 1: crescimento atrelado à variação do PIB & 15 minutos \\
\hline Cálculo da perpetuidade - alternativa 2: crescimento vegetativo & 15 minutos \\
\hline Cálculo da perpetuidade - alternativa 3: crescimento com inflação & 15 minutos \\
\hline Sensibilidade entre as alternativas - prós e contras, em grupos & 15 minutos \\
\hline Discussão sobre as alternativas - prós e contras, em plenária & 20 minutos \\
\hline Conclusões & 10 minutos \\
\hline
\end{tabular}

Fonte: Elaborado pelo autor.

O tempo do Quadro 1 totaliza 2,5 horas. Para níveis menores (graduação ou especialização), pode ser necessário um tempo até $1,5 \mathrm{x}$ maior.

Referências sugeridas para discussão de taxa de crescimento na perpetuidade: Gordon e Shapiro (1956), Palepu, Bernard e Healy (1997), Copeland, Koller e Murin (2002), Bradley e Jarrel (2008), Serra (2013), Jennergren (2013), Serra e Wickert (2014).

$\mathrm{Na}$ eventualidade de o caso ser utilizado para discutir todas as etapas de avaliação de empresas, sem o foco específico no cálculo da perpetuidade, aula pode seguir o plano sugerido no Quadro 2. 
Quadro 2 - Sugestão de organização da aula (alternativa de aplicação).

\begin{tabular}{|l|c|}
\hline Tarefa & Tempo \\
\hline Revisão dos passos para avaliar uma empresa & 15 minutos \\
\hline Apresentação do caso & 15 minutos \\
\hline Cálculo do Custo de Capital (WACC) & 20 minutos \\
\hline Modelagem da Receita Líquida & 20 minutos \\
\hline Modelagem do Resultado Bruto até o EBITDA & 20 minutos \\
\hline Modelagem do Capital de Giro Líquido & 20 minutos \\
\hline Modelagem do CAPEX e da Depreciação & 20 minutos \\
\hline Modelagem da Perpetuidade & 20 minutos \\
\hline $\begin{array}{l}\text { Cálculo do Firm Value, da Dívida Líquida, dos Ajustes por itens não operacionais e do } \\
\text { Equity Value }\end{array}$ & 20 minutos \\
\hline Conclusões & 10 minutos \\
\hline
\end{tabular}

Fonte: Elaborado pelo autor.

O tempo do Quadro 2 totaliza 3,0 horas. Para níveis menores (graduação ou especialização) pode ser necessário um tempo até 1,5x maior. Dependendo dos objetivos que o professor/instrutor tenha em mente, o tempo deve ser adequado. Alguns objetivos adicionais podem ser explorados, por exemplo, a discussão de:

(a) o custo de capital (premissas, estrutura de capital etc.),

(b) a projeção da receita líquida (outras lógicas),

(c) a projeção da DRE até o resultado operacional (considerando ganho de escala),

(d) a projeção das contas de capital de giro (uma a uma, considerando as lógicas comuns de prazo médio de recebimento, prazo médio de estoque, prazo médio de pagamento etc.), e

(e) a projeção de CAPEX.

Referências sugeridas para discussão de custo de capital: Meldrum (2000); Harvey (2001); Conover, Jensen e Johnson (2002); Goedhart e Haden (2003) e Lucey e Zhang (2007).

7 Projeção do Custo de Capital, das Demonstrações Financeiras, do Fluxo de Caixa e Questões a Serem Propostas

O custo de capital foi calculado com: (a) taxa livre de risco sendo a média do mês de março de 2017 , (b) prêmio país sendo a média do mês de março de 2017, (c) beta de 0,840 , (d) custo de dívida de $8,3 \%$ (considerando apenas os 3 maiores grupos de dívida da Tabela 3: Debêntures a um custo de 9,3\% a.a. (107,5\% da média simples da SELIC dos 5 anos de projeção), Arrendamento Mercantil a um custo de IPCA (média simples do IPCA dos 5 anos de projeção) mais 9,0\% a.a. e Resolução 4.131/62 a um custo de 6,0\% a.a. em $\mathrm{R} \$$ (considerando a Libor de $1,77 \%$ a.a., o cupom cambial de 2,1\% a.a., a inflação brasileira de $4,2 \%$ a.a. e a inflação americana de $2,1 \%$ a.a.), (e) peso de dívida no capital (D/(D+E)) de $17,40 \%$, baseado no firm value e equity value da Natura, (f) prêmio de mercado de $5,5 \%$ e (g) alíquota de imposto de renda corporativo (IR e CS) de 34,0\%. O custo de capital utilizado foi de 11,0\% a.a..

A receita líquida foi calculada por meio de um crescimento real e da inflação (do ano anterior). $O$ crescimento real foi obtido por meio da regressão entre o crescimento histórico do setor de Higiene Pessoal, Perfumaria e Cosméticos e a variação do PIB (Tabela 4). Considerou-se que o market share da Natura ficará constante, portanto, seu crescimento será igual ao crescimento do setor de HPPC. O intercepto da regressão não é significativo (valor-p 0,170), o coeficiente angular da regressão é 1,284 (valor-p 0,034) e o coeficiente de ajuste $\left(R^{2}\right)$ é de 0,45 . Observa-se que, se o ano 2015 fosse retirado da amostra (considerado outlier), o resultado da regressão seria pior.

O resultado operacional foi projetado com base na margem operacional média dos últimos 3 anos (2014, 2015 e 2016). A Tabela 9 apresenta os resultados. 
Tabela 9 - Projeção (i) da receita líquida (com respectivos crescimentos, real e nominal) e (ii) do resultado operacional.

\begin{tabular}{lccccc}
\hline & $\mathbf{2 0 1 7} \mathbf{P}$ & $\mathbf{2 0 1 8} \mathbf{P}$ & $\mathbf{2 0 1 9} \mathbf{P}$ & $\mathbf{2 0 2 0} \mathbf{P}$ & $\mathbf{2 0 2 1} \mathbf{P}$ \\
\hline Variação do PIB & $0,5 \%$ & $2,5 \%$ & $2,6 \%$ & $2,5 \%$ & $2,5 \%$ \\
IPCA $_{\mathrm{t}-1}$ & $6,28 \%$ & $4,09 \%$ & $4,38 \%$ & $4,31 \%$ & $4,28 \%$ \\
& & & & & \\
Crescimento Real & $0,60 \%$ & $3,16 \%$ & $3,30 \%$ & $3,22 \%$ & $3,17 \%$ \\
Crescimento Nominal & $6,92 \%$ & $7,38 \%$ & $7,82 \%$ & $7,67 \%$ & $7,59 \%$ \\
& & & & & \\
[R\$ Milhões] & $2017 \mathrm{P}$ & $2018 \mathrm{P}$ & $2019 \mathrm{P}$ & $2020 \mathrm{P}$ & $2021 \mathrm{P}$ \\
Vendas Líquidas & $8.460,4$ & $9.084,6$ & $9.795,4$ & $10.546,9$ & $11.347,1$ \\
Resultado Operacional & $1.353,7$ & $1.453,5$ & $1.567,3$ & $1.687,5$ & $1.815,5$ \\
Margem Operacional & $16,0 \%$ & $16,0 \%$ & $16,0 \%$ & $16,0 \%$ & $16,0 \%$ \\
\hline
\end{tabular}

Fonte: Elaborada pelo autor.

Foram consideradas as seguintes contas como capital de giro líquido: (a) no ativo: contas a receber, estoque, impostos a recuperar de curto prazo, outros ativos circulantes e um caixa operacional estimado em $2 \%$ da receita líquida anual e (b) no passivo: contas a pagar, salários e encargos a pagar, impostos a pagar e outros passivos circulantes. O porcentual médio de capital de giro líquido em relação às vendas líquidas (para 2015 e 2016) foi mantido constante para o horizonte de projeção.

$\mathrm{O}$ ativo fixo foi projetado considerando o imobilizado e o intangível. $\mathrm{O}$ índice ativo fixo líquido dividido pelas vendas líquidas (em porcentual) foi considerado fixo ao longo do horizonte de projeção (média de 2015 e 2016). O imobilizado líquido foi projetado a partir deste índice e das vendas líquidas projetadas. A alíquota de depreciação foi calculada com base no imobilizado bruto do ano anterior (poderia ter sido sobre o imobilizado médio) e mantida constante (média de 2015 e 2016). Calculou-se a depreciação de cada período a partir da alíquota de depreciação aplicada ao imobilizado bruto do ano anterior. A depreciação acumulada foi calculada a partir da depreciação acumulada até o período anterior somada à depreciação do próprio período. O imobilizado bruto foi calculado por meio da soma do imobilizado líquido com a depreciação acumulada. O investimento em ativo fixo (CAPEX) foi calculado pela diferença entre o ativo fixo do próprio ano e o ativo fixo do ano anterior.

A Tabela 10 apresenta os valores do imobilizado e do capital de giro líquido, inclusive a depreciação do período, o CAPEX e o investimento em capital de giro líquido.

Tabela 10 - Evolução do capital de giro líquido e do imobilizado da Natura.

Painel (a): Capital de Giro Líquido (CGL)

\begin{tabular}{|c|c|c|c|c|c|c|c|}
\hline [R\$ Milhões] & $2015 R$ & $2016 R$ & $2017 \mathrm{P}$ & $2018 P$ & $2019 P$ & $2020 P$ & $2021 P$ \\
\hline Ativo & $2.658,5$ & $2.662,2$ & & & & & \\
\hline Passivo & $(2.220,9)$ & $(2.260,2)$ & & & & & \\
\hline Capital de Giro Líq. (CGL) & 437,6 & 402,0 & 448,4 & 481,5 & 519,2 & 559,0 & 601,4 \\
\hline Investimento em CGL & & & 46,4 & 33,1 & 37,7 & 39,8 & 42,4 \\
\hline CGL / Receita Líquida & $5,5 \%$ & $5,1 \%$ & $5,3 \%$ & $5,3 \%$ & $5,3 \%$ & $5,3 \%$ & $5,3 \%$ \\
\hline \multicolumn{8}{|l|}{ Painel (b): Imobilizado } \\
\hline [R\$ Milhões] & $2015 R$ & $2016 \mathrm{R}$ & $2017 \mathrm{P}$ & $2018 \mathrm{P}$ & $2019 P$ & $2020 \mathrm{P}$ & $2021 \mathrm{P}$ \\
\hline Ativo Fixo Bruto & $3.679,8$ & $3.774,2$ & $4.255,0$ & $4.766,6$ & $5.343,5$ & $5.975,6$ & $6.669,5$ \\
\hline (-) Depreciação Acumulada & $(1.111,0)$ & $(1.255,3)$ & $(1.530,8)$ & $(1.841,4)$ & $(2.189,4)$ & $(2.579,5)$ & $(3.015,7)$ \\
\hline (=) Ativo Fixo Líquido & $2.568,8$ & $2.518,9$ & $2.724,2$ & $2.925,2$ & $3.154,1$ & $3.396,1$ & $3.653,8$ \\
\hline \% Receita Líquida & $32,5 \%$ & $31,8 \%$ & $32,2 \%$ & $32,2 \%$ & $32,2 \%$ & $32,2 \%$ & $32,2 \%$ \\
\hline
\end{tabular}




\begin{tabular}{llllllll}
\hline Depreciação do Período & 239,2 & 260,8 & 275,5 & 310,6 & 348,0 & 390,1 & 436,2 \\
Alíquota de Depreciação & $7,5 \%$ & $7,1 \%$ & $7,3 \%$ & $7,3 \%$ & $7,3 \%$ & $7,3 \%$ & $7,3 \%$ \\
\hline CAPEX & & & 480,8 & 511,6 & 576,9 & 632,1 & 693,9 \\
\hline
\end{tabular}

Fonte: Elaborada pelo autor.

O fluxo de caixa, a partir das informações da Tabela 9 e da Tabela 10, está apresentado na Tabela 11:

Tabela 11 - Fluxo de caixa.

\begin{tabular}{llllll}
\hline & $2017 \mathrm{P}$ & $2018 \mathrm{P}$ & $2019 \mathrm{P}$ & $2020 \mathrm{P}$ & $2021 \mathrm{P}$ \\
\hline Resultado Operacional & $1.353,7$ & $1.453,5$ & $1.567,3$ & $1.687,5$ & $1.815,5$ \\
(-) IR Operacional & $(460,3)$ & $(494,2)$ & $(532,9)$ & $(573,8)$ & $(617,3)$ \\
(+) Depreciação & 275,5 & 310,6 & 348,0 & 390,1 & 436,2 \\
(-) CAPEX & $(480,8)$ & $(511,6)$ & $(576,9)$ & $(632,1)$ & $(693,9)$ \\
$(-)$ Investimento em CGL & $(46,4)$ & $(33,1)$ & $(37,7)$ & $(39,8)$ & $(42,4)$ \\
\hline (=) Fluxo de Caixa & 641,7 & 725,2 & 767,8 & 831,9 & 898,1 \\
\hline
\end{tabular}

Fonte: Elaborada pelo autor.

O dilema do caso é como montar a perpetuidade. Possíveis questões propostas para o debate são:

(a) qual, entre as 3 lógicas de crescimento propostas, adotar?

(b) crescer, sempre agrega valor?

(c) caso assuma que crescer não agrega valor, qual a relevância do crescimento real para avaliar a empresa? Neste caso, ele pode ser ignorado no cálculo da perpetuidade?

(d) qual foi a lógica adotada nos 3 laudos disponibilizados (Tabela 8)?

(e) qual ajuste foi realizado para manter a coerência entre o crescimento real adotado e o fluxo de caixa base da perpetuidade?

(f) caso seja adotada a premissa de que crescer agrega valor, quais cuidados devem ser tomados (coerência entre o crescimento real e o fluxo de caixa base da perpetuidade)?

A solução abaixo considera que crescer não agrega valor, sob a competitive equilibrium assumption (valor presente líquido dos novos projetos será zero, ou seja, a taxa de retorno dos mesmos será considerada igual ao custo de capital). Neste sentido, adotou-se a taxa de crescimento real igual a zero, a taxa de crescimento nominal igual a inflação de longo prazo e o investimento líquido em ativo fixo igual a zero (CAPEX = depreciação) no fluxo de caixa base da perpetuidade. A Tabela 12 indica o fluxo de caixa base da perpetuidade e o seu valor.

Tabela 12 - Fluxo de caixa base e cálculo da perpetuidade (em 2021).

\begin{tabular}{lc}
\hline [R\$ Milhões] & $2021 \mathrm{Aj}$ \\
\hline Resultado Operacional & $1.815,5$ \\
(-) IR Operacional & $(617,3)$ \\
(+) Depreciação & 436,2 \\
(-) CAPEX & $(436,2)$ \\
(-) Investimento em CGL & $(42,4)$ \\
\hline (=) Fluxo de Caixa & $1.155,8$ \\
WACC & \\
Crescimento & \\
\hline Perpetuidade (em 2021) & $11,0 \%$ \\
\hline \hline
\end{tabular}

Observação: Perpetuidade calculada, no Exce ${ }^{\circledR}$ e com todas as casas decimais, como 1.155,8 x $(1+4,2 \%) /(11,0 \%-4,2 \%)$. Fonte: Elaborada pelo autor. 
Considerando o fluxo de caixa (Tabela 11), a perpetuidade (Tabela 12), o custo de capital, o excesso de caixa (caixa e aplicações financeiras menos o caixa operacional considerado em $2 \%$ da receita líquida) e demais premissas, calcula-se o firm value, o equity value e o valor por ação (considerando 430,3 milhões de ações), conforme a Tabela 13:

Tabela 13 - Firm value, equity value e valor por ação da Natura em 31 de dezembro de 2016.

\begin{tabular}{lc}
\hline Firm Value [R\$ milhões] & $13.319,9$ \\
\hline (-) Dívida Bruta & $(4.390,2)$ \\
(-) Dividendos Declarados & $(79,7)$ \\
(+) Excesso de Caixa & $2.140,6$ \\
(+) Outros Ativos & $1.099,7$ \\
(-) Outros Passivos & $(695,1)$ \\
\hline (=) Equity Value & $11.395,3$ \\
\# Ações (em milhões) & 430,3 \\
\hline Preço por ação (em R\$) & 26,48 \\
\hline
\end{tabular}

Obs.: Os ajustes do Firm Value para o Equity Value consideram a dívida líquida (dívida bruta menos excesso de caixa) e itens não operacionais e não financeiros (outros ativos e outros passivos). Dividendos declarados podem ser considerados como dívida da empresa para com os (antigos) acionistas no momento da declaração.

Fonte: Elaborada pelo autor.

O cálculo do equity value considera, especificamente: (1) Dívida bruta composta pelos empréstimos e financiamentos de curto e longo prazo, (2) excesso de caixa composto pelos caixa, equivalentes e aplicações financeiras menos a parcela de caixa considerada caixa operacional ( $2 \%$ da receita líquida), (3) outros ativos compostos pelos impostos a recuperar de longo prazo, impostos diferidos, depósitos judiciais e outros ativos não circulantes e (4) outros passivos compostos por instrumentos derivativos, impostos a pagar de longo prazo, impostos diferidos de longo prazo, provisões trabalhistas, cíveis e tributárias e outros passivos não circulantes. Todos os valores foram obtidos no balanço (Tabela 1) de 31 de dezembro de 2016, a data base da avaliação.

O preço por ação obtido, utilizando-se as premissas descritas anteriormente, é de $R \$ 26,48$, em 31 de dezembro de 2016. A ação fechou 31 de dezembro de 2016 a $R \$ 23,02$ e 31 de março de 2017 a $R \$$ 29,01 .

\section{Referências}

Associação Brasileira da Indústria de Higiene Pessoal, Perfumaria e Cosméticos -ABIHPEC.Panorama do setor de higiene pessoal, perfumaria e cosméticos. Disponível em: <https://abihpec.org.br/ publicacao/panorama-do-setor-2016-2/>. Acesso em: 15 abr 2017.

BANCO MUNDIAL. Disponível em: <https://www.google.com.br/publicdata/explore? ds=d5bncppjof8f9_\&met_y=sp_pop_grow\&idim=country:BRA\&hl=pt\&dl=pt\#!ctype=l\&strail=false\&bcs=d\& nselm=h\&met_y=sp_pop_grow\&scale_y=lin\&ind_y=false\&rdim=region\&idim=country:BRA\&ifdim=region\& tstart=957236400000\&tend=1430535600000\&hl=pt\&dl=pt\&ind=false>. Acesso em: 15 abr 2017.

BRADLEY, M. H.; JARREL, G. A. Expected inflation and the constant-growth valuation model. Journal of Applied Corporate Finance, [S.I], v. 20, n. 2, p. 66-78, Jul. 2008.

CONOVER, C. M.; JENSEN, G. R.; JOHNSON, R. R. Emerging markets: when are they worth it? Financial Analysts Journal, [S.I], v. 58, n. 2, p. 86-95, Mar.-Apr. 2002.

COPELAND, T. E.; KOLLER, T.; MURRIN, J. Avaliação de empresas - valuation: Calculando e gerenciando valor das empresas. São Paulo: Pearson Makron Books, 2002.

DAMODARAN, A. Avaliação de empresas. São Paulo: Pearson Prentice Hall, 2007. 
GORDON, M. J.; SHAPIRO, E. Capital equipment analysis: the required rate of profit. Management Science, [S.I], v. 3, n. 1, p. 102-110, Oct. 1956.

HARVEY, C. R. Asset pricing in emerging markets. International Encyclopedia of the Social \& Behavioral Sciences. Oxford, p.840-845, 2001. Disponível: <https://www.sciencedirect.com/science/ article/pii/B0080430767022683>. Acesso em: 15 abr 2017.

JENNERGREN, L. P. Technical Note: value driver formulas for continuing value in firm valuation by the discounted cash flow model. The Engineering Economist, [S.I], v. 58, n. 1, p. 59-70, Jan. 2013.

Lucey, B. M.; Zhang, Q. Integration analysis of Latin American stock markets 1993-2007. Disponível em: <https://ssrn.com/abstract=1047421>. Acesso em: 15 abr. 2017.

MARTELANC, R.; PASIN, R.; PEREIRA, F. Avaliação de empresas: um guia para fusões \& aquisições e private equity. São Paulo: Pearson, 2010.

MELDRUM, D. H.. Country risk and foreign direct investment. Business Economics, [S.I], v. 35, n. 1, p. 33-40, Jan. 2000.

NATURA. Demonstrações Financeiras 2016. Disponível em: <http://natu.infoinvest.com.br/ ptb/5570/ Demonstraes\%20financeiras\%20anuais\%20completas\%202015\%20_v2.pdf>. Acesso em: 15 abr 2017.

Demonstrações Financeiras. Disponível em: <http://natu.infoinvest.com.br/ ptb/5907/

Demonstraes\%20financeiras\%204T16\%20-\%20Portugus\%20com\%20ata.pdf>. Acesso em: $15 \mathrm{abr}$ 2017.

Encontro com os acionistas 2017. Disponível em: <http://natu.infoinvest.com.br/ptb/6000/ Encontro\%20Acionistas\%202017\%20VF\%20pt.pdf>. A Acesso em: 15 abr 2017a.

Relatório anual de 2016. Disponível em: <http://natu.infoinvest.com.br/ ptb/3895/ ReltorioAnual2006.pdf>. Acesso em: 15 abr 2017 b.

PALEPU, K. G.; BERNARD, V. L; HEALY, P. M. Introduction to business analysis \& valuation. Ohio: South-Western Publishing Co, 1997.

SERRA, R. G. Determinação da taxa de crescimento na perpetuidade em avaliação de empresas.

Revista de Finanças Aplicadas, [S.I], v. 1, n. 1, p. 1-20, 2013.

SERRA, R. G.; WICKERT, M. Valuation: guia fundamental. São Paulo: Altas.

Submetido em: 05/05/2017

Aprovado em: 04/01/2018 